\title{
Curcumin-Loaded Nanoparticle for Breast Cancer Synergistic Theranostics: Design, in vitro and in vivo Evaluation
}

This article was published in the following Dove Press journal:

International Journal of Nanomedicine

\author{
Chong Huang ${ }^{1,2}$ \\ Fen Chen ${ }^{3,4}$ \\ Ling Zhang ${ }^{5}$ \\ Yue Yang ${ }^{2}$ \\ Xinggang Yang ${ }^{2}$ \\ Weisan Pan (D) $^{2}$ \\ 'School of Traditional Chinese Medicine, \\ Shenyang Pharmaceutical University, \\ Shenyang II0016, People's Republic of \\ China; ${ }^{2}$ School of Pharmacy, Shenyang \\ Pharmaceutical University, Shenyang \\ I 100I6, People's Republic of China; ${ }^{3}$ Key \\ Laboratory of Ministry of Education for \\ TCM Viscera-State Theory and \\ Applications, Liaoning University of \\ Traditional Chinese Medicine, Shenyang \\ I I 0847, People's Republic of China; \\ ${ }^{4}$ Zhejiang Jingxin Pharmaceutical Co., Ltd, \\ Xinchang 3/2500, People's Republic of \\ China; ${ }^{5}$ Department of Biotherapy, \\ Cancer Research Institute, The First \\ Affiliated Hospital of China Medical \\ University, Shenyang I I000I, People's \\ Republic of China
}

Correspondence: Weisan Pan School of Pharmacy, Shenyang Pharmaceutical University, 103 Wenhua Road, Shenyang I I00 I6, People's Republic of China

Tel +8624239863l3

Email pppwwwsss@163.com

Fen Chen

Key Laboratory of Ministry of Education for TCM Viscera-State Theory and Applications, Liaoning University of Traditional Chinese Medicine, 79

Chongshan East Road, Shenyang I I0847,

People's Republic of China

Tel +86 2431207125

Email chenfenII2I@I63.com
Background: Emerging cancer therapy requires highly sensitive diagnosis in combination with cancer-targeting therapy. In this study, a self-assembled $\mathrm{pH}$-sensitive curcumin (Cur)loaded nanoparticle of ${ }^{99 \mathrm{~m}} \mathrm{Tc}$ radiolabeled hyaluronan-cholesteryl hemisuccinate conjugates (HA-CHEMS) and D-a-tocopheryl polyethylene glycol succinate (TPGS) was prepared for breast cancer synergistic theranostics.

Materials and Methods: The synthesized amphiphilic HA-CHEMS conjugates and TPGS self-assembled into Cur-loaded nanoparticles (HA-CHEMS-Cur-TPGS NPs) in an aqueous environment. The physicochemical properties of HA-CHEMS-Cur-TPGS NPs were characterized by transmission electron microscopy (TEM) and dynamic lighter scattering (DLS). The in vitro cytotoxicity of HA-CHEMS-Cur-TPGS NPs against breast cancer cells was evaluated by using the methyl thiazolyl tetrazolium (MTT) assay. Moreover, the in vivo animal experiments of HA-CHEMS-Cur-TPGS NPs including SPECT/CT imaging biodistribution and antitumor efficiency were investigated in $4 \mathrm{~T} 1$ tumor-bearing BALB/c mice; furthermore, pharmacokinetics were investigated in healthy mice.

Results: HA-CHEMS-Cur-TPGS NPs exhibited high curcumin loading, uniform particle size distribution, and excellent stability in vitro. In the cytotoxicity assay, HA-CHEMS-CurTPGS NPs showed remarkably higher cytotoxicity to 4T1 cells with an IC50 value at $38 \mu \mathrm{g} /$ $\mathrm{mL}$, compared with free curcumin $(77 \mu \mathrm{g} / \mathrm{mL})$. Moreover, HA-CHEMS-Cur-TPGS NPs could be effectively and stably radiolabeled with ${ }^{99 \mathrm{~m}} \mathrm{Tc}$. The SPECT images showed that ${ }^{99} \mathrm{~m}$ Tc-HA-CHEMS-Cur-TPGS NPs could target the $4 \mathrm{~T} 1$ tumor up to $4.85 \pm 0.24 \% \mathrm{ID} / \mathrm{g}$ at $4 \mathrm{~h}$ post-injection in BALB/c mice. More importantly, the in vivo antitumor efficacy studies showed that HA-CHEMS-Cur-TPGS NPs greatly inhibited the tumor growth without resulting in obvious toxicities to major organs.

Conclusion: The results indicated that HA-CHEMS-Cur-TPGS NPs with stable ${ }^{99 \mathrm{~m}} \mathrm{Tc}$ labeling and high curcumin-loading capacity hold great potential for breast cancer synergistic theranostics.

Keywords: curcumin, hyaluronan, nanoparticle, cancer theranostics

\section{Introduction}

Breast cancer is one of the main threats to women's health and has become the number one cancer among women. ${ }^{1}$ Chemotherapy, one of the major clinical treatments for breast cancer, still faces many problems, such as poor bioavailability and severe side effects of the active ingredients. Curcumin, a natural polyphenol 
molecule derived from the Zingiberaceae and Araceae plants has proved to be antineoplastic. However, its clinical application has been limited because of its low solubility and rapid metabolism in vivo. ${ }^{2-9}$ In the past decades, nanocarriers have been rapidly developed for drug delivery to increase solubility, prolong duration in vivo, improve tumor-selective cytotoxicity, and reduce drug exposure to normal tissues including polymeric nanoparticles, inorganic nanoparticles, and liposomes. ${ }^{10-18}$ Polymeric nanocarriers may be composed of a synthetic polymer or natural polymer, both of which have exhibited good biocompatibility, an easily manipulated chemical structure, and stimuli-responsiveness. ${ }^{19-22}$

Hyaluronic acid, also called hyaluronan (HA), a natural polysaccharide, consists of repeating disaccharide units and has been widely used for its biocompatibility. HA can target to CD44-overexpressed solid cancer and cancer stem cells, such as breast, lung, and prostate cancers. ${ }^{23-28}$ By modifying hydrophobic segments, HA-derivatives could self-assemble into nanoparticles that could be used for chemotherapeutics delivery. ${ }^{29,30}$ For instance, Jeannot et al reported HA-b-poly( $\gamma$-benzyl-L-glutamate) nanoparticles that could actively target to the CD44 receptor for delivery of vorinostat and gefitinib with strong tumor growth inhibition. ${ }^{31}$ In another example, Gu et al synthesized HA-b-poly(trimethylene carbonate-co-dithiolane trimethylene carbonate) that was capable of high drug loading and tumor-targeted delivery of bortezomib to myeloma in vivo. The HA-based nanoparticles exhibited a broad therapeutic window and enhanced tolerance with more effective growth suppression of CD44-overexpressed tumors. ${ }^{32}$

D-a-tocopheryl polyethylene glycol succinate (TPGS) is a lipophilic polymer derivative of natural vitamin $\mathrm{E}$, it has been approved by the FDA for stabilization in drug delivery systems. Recent studies have shown that TPGS could play a role as an anticancer drug enhancer by inhibiting P-glycoprotein-mediated multidrug resistance in multiple tumor cells. ${ }^{33-38}$ However, few investigations have involved the combination functions of therapy and diagnosis.

Compared with fluorescence imaging, nuclear imaging provides infinite penetration depth and quantitative capability. ${ }^{39}$ In particular, single photon emission computer tomography (SPECT) provides non-invasive detection with high sensitivity and quantification suitable for diagnosis which can be conducive to optimizing the dosing schedule for precise treatment.
Technetium-99m $\left({ }^{99 \mathrm{~m}} \mathrm{Tc}\right)$, obtained from the ${ }^{99} \mathrm{Mo}-{ }^{99 \mathrm{~m}} \mathrm{Tc}$ generator, is readily available and inexpensive. It has become used daily as a radionuclide in clinics for its favorable physical and chemical properties, including a low energy gamma emission of $140 \mathrm{keV}$ and a half-life of $6 \mathrm{~h} .{ }^{40}$ For example, HA radiolabeled with ${ }^{99 \mathrm{~m}} \mathrm{Tc}$ could provide quantitative information on the biodistribution and pharmacokinetic of HA. ${ }^{41} \mathrm{By}$ labeling with ${ }^{99 \mathrm{~m}} \mathrm{Tc}$, tumor-targeting nanoparticles could help guide tumor diagnosis. For instance, Polyak et al established a ${ }^{99 \mathrm{~m}} \mathrm{Tc}$ radiolabeled nanoparticles that self-assembled by chitosan and folated poly- $\gamma$-glutamic acid, which was regarded as a tumor-targeting imaging agent for folate-receptor-overexpressing tumors and exhibited enhanced contrast in mice models. ${ }^{42}$ With ${ }^{99 \mathrm{~m}} \mathrm{Tc}$ radiolabeling, nanoparticles could facilitate non-invasive quantitative diagnosis and allow for personalized treatments by utilizing the same nanoparticles.

In our previous study, we synthesized amphiphilic HAcholesteryl hemisuccinate conjugates that self-assembled into docetaxel-loaded nanoparticles with high drug loading, excellent stability in vitro and efficient antitumor effects. ${ }^{43}$ In this study, we synthesized HA-CHEMS with 20kd HA, which was higher than the 7.6kd HA which previously reported. The higher molecular weight HA may provide greater charge shielding and higher affinity with CD44 receptors. ${ }^{44}$ Then, we prepared HA-CHEMS and TPGS nanoparticles as a carrier to deliver curcumin for actively targeting to CD44- overexpressed tumors. Furthermore, radiolabeled with ${ }^{99 \mathrm{~m}} \mathrm{Tc}$, the nanocarrier was developed as a nuclear imaging agent of SPECT imaging and quantification of the tumor targeting ability. On the one hand, HA could serve as a vector that could actively target to CD44-overexpressed tumor cells and tumor stem cells and interfere with endogenous HA-CD44 interaction. On the other hand, curcumin and TPGS could be released by the low $\mathrm{pH}$ of lysosome in tumor cells generating the potential for synergistic therapy (Figure 1).

\section{Materials and Methods Materials}

Sodium hyaluronic acid (molecular weight: $20 \mathrm{kDa}$ ) was provided by Shandong Freda Biopharm Co. Ltd). Sodium pertechnetate $\left(\mathrm{Na}^{99 \mathrm{~m}} \mathrm{TcO}_{4}{ }^{-}\right)$was supplied by Shanghai GMS Pharmaceutical Co. Ltd. All chemicals were purchased commercially and used without further purification. The 4T1 mice mammary cancer cells were purchased from the cell bank of the Chinese Academy of Sciences (Shanghai, People's Republic of China). 


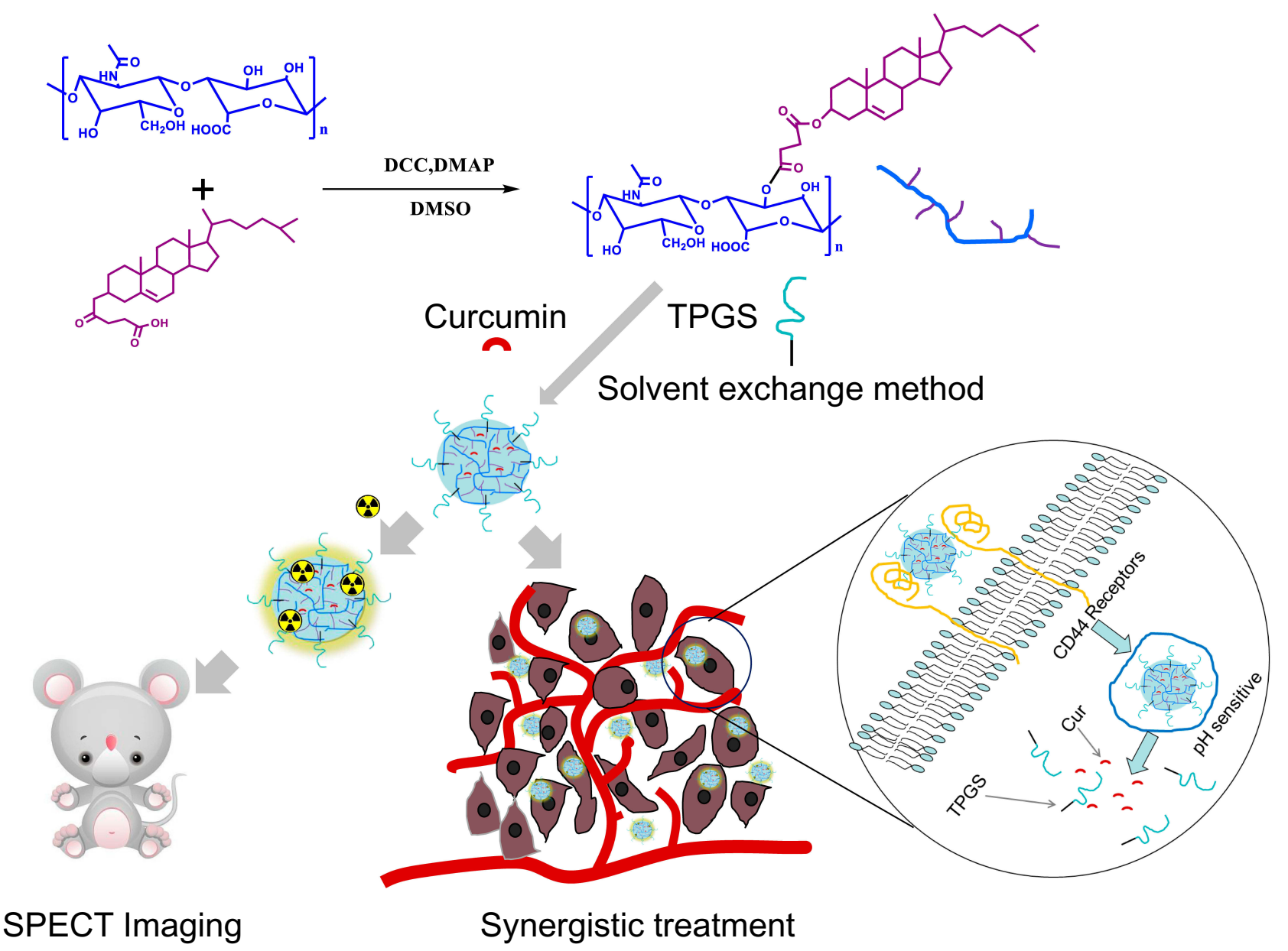

Figure I Schematic illustration of the preparation of HA-CHEMS-Cur-TPGS NPs, SPECT imaging and synergistic treatment.

Female BALB/C mice (6 weeks of age, 20-23 g) of specific pathogen-free grade were received from the Shanghai SLAC Laboratory Animal Co., Ltd. All of the animal experiments were carried out in compliance with the guidelines for the Care and Use of Laboratory Animals of Shenyang Pharmaceutical University. Ethical approval was obtained for the use of animals in this study from the review board for the Care and Use of Cells/Laboratory Animals of Shenyang Pharmaceutical University.

\section{Preparation and Characterization of Nanoparticles}

HA-cholesteryl hemisuccinate (HA-CHEMS) was synthesized via an esterification reaction. Briefly, cholesteryl hemisuccinate $(40 \mathrm{mg}$ ) and DCC (34 mg) were dissolved in DMSO $(2 \mathrm{~mL})$, and then stirred for $4 \mathrm{~h}$ at $30{ }^{\circ} \mathrm{C}$. Then, HA (160 mg) and DMAP (4 mg) were added to the mixture and reacted for $3 \mathrm{~d}$. Thereafter, the mixture was dialyzed in DMSO three times and in water six times, which was followed by lyophilizing. The yield was 90.3\%. Moreover, the ${ }^{1} \mathrm{H}$ NMR spectra of HA-CHEM was recorded by UNITY INOVA. ( $\mathrm{D}_{2} \mathrm{O} / \mathrm{DMSO}-\mathrm{d} 6$, 400MHz, $\delta)$ : HA (1.76, 4.44, and 7.43) CHEMS (5.33).

The curcumin-loaded HA-CHEMS and TPGS mixed nanoparticles (HA-CHEMS-Cur-TPGS NPs) were prepared using the membrane dialysis method as previously described. Briefly, HA-CHEMS $(5 \mathrm{mg} / \mathrm{mL}, 200 \mu \mathrm{L})$, curcumin $(1 \mathrm{mg} / \mathrm{mL}, 100 \mu \mathrm{L})$, and TPGS $(10 \mathrm{mg} / \mathrm{mL}, 10 \mu \mathrm{L})$ were dissolved in DMSO, and then the mixed solution was dropwise injected into a phosphate buffer solution (PBS, $10 \mathrm{mM}, \mathrm{pH}$ 7.4). After a half hour, the unloaded curcumin and DMSO were removed using dialysis against the PBS $(10 \mathrm{mM})$ for $8 \mathrm{~h}$. The same method was used for the preparation of the HA-CHEMS nanoparticles, HACHEMS-TPGS nanoparticles, and curcumin-loaded HACHEMS (HA-CHEMS-Cur) nanoparticles.

The hydrodynamic size and zeta potential of the nanoparticles was measured using dynamic light scattering 
(DLS). All experiments were conducted on a Malvern Zetasizer Nano ZS90 (a solid-state He-Ne laser $(\lambda=633$ $\mathrm{nm})$ ) at $20{ }^{\circ} \mathrm{C}$ and repeated three times. To visualize the morphology of HA-CHEMS-Cur-TPGS NPs, the nanoparticle suspension was dropped on copper grids with films and recorded by transmission electron microscopy (TEM, FEI Tecnai F20). The colloidal stability of HA-CHEMSCur-TPGS NPs was measured for 1 week.

For the measurement of entrapment efficiency (EE) and drug loading (DL), $0.2 \mathrm{~mL}$ of nanoparticles suspension prepared as described above was mixed with $9.8 \mathrm{~mL}$ of DMSO. This was followed by sonication disruption for $15 \mathrm{~min}$ and centrifugation for $10 \mathrm{~min}$ at $8000 \mathrm{rpm}$. The Cur content in the supernatant was assayed by HPLC.

To investigate the release behavior of curcumin from HA-CHEMS-Cur-TPGS NPs, HA-CHEMS-Cur-TPGS NPs suspension $(1 \mathrm{mg} / \mathrm{mL}, 1 \mathrm{~mL})$ was dialyzed against PBS $(10 \mathrm{mM})$ at a $\mathrm{pH}$ of 5.0, 6.5 and 7.4.

\section{${ }^{99 \mathrm{~m}} \mathrm{Tc}$ Radiolabeling of Nanoparticles}

Stannous chloride $(10 \mu \mathrm{L}, 1 \mathrm{mg} / \mathrm{mL})$ was added to sodium pertechnetate $\left(\mathrm{Na}^{99 \mathrm{~m}} \mathrm{TcO}_{4}{ }^{-}, 200 \mu \mathrm{Ci}\right)$ solution and then added to the HA-CHEMS-Cur-TPGS NPs $(100 \mu \mathrm{L}, 1$ $\mathrm{mg} / \mathrm{mL}$ ). After 30 minutes, the reaction was stopped by adding sodium disulfate $(10 \mu \mathrm{L}, 10 \mathrm{mg} / \mathrm{mL})$. Finally, the suspension was passed through a PD-10 desalting column to isolate the spare ${ }^{99 \mathrm{~m}} \mathrm{Tc}$. The radiolabeling efficiency was determined by the activity of nanoparticles fraction divided the activity of all fractions. The radiostability was examined using a gel chromatography assay using the PBS as a mobile phase.

\section{In vitro Cytotoxicity}

The 4T1 mice mammary cancer cells were cultured in a Dulbecco's Modified Eagle's medium (DMEM) supplemented with feta bovine serum (10\%, FBS) in a humidified atmosphere of $5 \% \mathrm{CO}_{2}$ at $37{ }^{\circ} \mathrm{C}$. The previous study demonstrated that the expression level of CD44 was high on the surface of $4 \mathrm{~T} 1$ cells.

The comparison of cytotoxicity of different HA nanoparticles was performed on 4T1 cells. The 4T1 cells were seeded in a 96-well plate and cultured for $24 \mathrm{~h}$ at $37^{\circ} \mathrm{C}$ before treatment. Then, the medium was replaced by different nanoparticle suspensions at various curcumin concentrations for $24 \mathrm{~h}$ at $37{ }^{\circ} \mathrm{C}$. Next, the cells were incubated with 3-(4,5-dimethylthiazol-2-yl)-2,5-diphenyltetrazolium bromide solution $(100 \mu \mathrm{L}, 0.5 \mathrm{mg} / \mathrm{mL})$ for another $4 \mathrm{~h}$. After that, dimethyl sulfoxide (DMSO) was added to dissolve the formazan crystals. The absorbance of each well was measured using the microplate reader (Thermo, Vrioskan Flash).

\section{SPECT/CT Imaging and Biodistribution in Tumor-Bearing Mice}

In vivo imaging was conducted on a microSPECT/CT scanner with an energy window from $120 \mathrm{keV}$ to $160 \mathrm{keV}$ for all scans. The 4T1 cell suspension $\left(\square 5 \times 10^{6}\right.$ cells) was subcutaneously injected into the flank region on the right side of the mouse's back to establish the tumor model. When the average volume of the tumor reached $40-50 \mathrm{~mm}^{3}$, the tumor-bearing mice were intravenously injected with ${ }^{99 \mathrm{~m}} \mathrm{Tc}-\mathrm{HA}-\mathrm{CHEMS}-\mathrm{Cur}-$ TPGS NPs $(20 \mathrm{mg} / \mathrm{kg}, 500 \mu \mathrm{Ci})$ via the tail vein. The scan was performed at predetermined time intervals after administration $(0,2,4,6,8$ and $24 \mathrm{~h})$. As a control, $3 \mathrm{BALB} / \mathrm{c}$ mice were injected with HA polymer $(1 \mathrm{mg} / \mathrm{mL}) 1$ hour before injection of ${ }^{99 \mathrm{~m}}$ Tc-HA-CHEMS-Cur-TPGS NPs.

To study the in vivo plasma pharmacokinetic, blood samples were collected from the retinal veins of healthy BALB/c mice $(\mathrm{n}=3)$ at $0,1,2,4,6,8$ and $24 \mathrm{~h}$ after injection of the ${ }^{99 \mathrm{~m}} \mathrm{Tc}-\mathrm{HA}-\mathrm{CHEMS}-\mathrm{Cur}-\mathrm{TPGS}$ NPs. The radioactivity of blood samples was measured by a $\gamma$ counter (Multi Crystal LB $2111 \gamma$ counter). The biodistribution of the ${ }^{99 \mathrm{~m}}$ Tc-HA-CHEMS-Cur-TPGS NPs was studied by measuring the radioactivity of major organs (heart, kidneys, liver, lungs, and spleen).

\section{In vivo Antitumor Efficacy and Toxicity}

The antitumor efficacy was evaluated by using the mouse flank tumor model bearing murine breast $4 \mathrm{~T} 1$ cells. When the average volume of the tumor reached $40-50 \mathrm{~mm}^{3}$, the mice were randomly divided into four groups $(n=5)$, receiving different injections as follows: (1) HACHEMS NPs (the control group), (2) HA-CHEMS-Cur NPs, (3) HA-CHEMS-TPGS NPs, and (4) HA-CHEMSCur-TPGS NPs $(50 \mathrm{mg} / \mathrm{kg})$. The nanoparticles were given every 2 days for a total of 5 times. The tumor volume and body weight were measured every 2 days. The survival of mice was also recorded. At the end of the experiment, the tumor and main organs of the mice were sectioned into thin slices for H\&E and TUNEL staining.

\section{Statistical Analysis}

One-way analysis of variance (ANOVA) was carried out to evaluate the significance between groups, and post-hoc 
tests with the Bonferroni correction were used for comparison among individual groups. ${ }^{*} \mathrm{p}<0.05$ was considered significant, and $* * p<0.01$ were considered highly significant. All data were presented as mean \pm standard deviation.

\section{Results and Discussion \\ Preparation and Characterization of HA- CHEMS-Cur-TPGS Nanoparticles}

HA-CHEMS was obtained by conjugating cholesteryl hemisuccinate (CHEMS) with HA via an esterification reaction in the presence of DCC, DMAP, and DMSO for 3 days according to our previous protocols (Figure 1). ${ }^{43}$ As shown in Figure 2, the ${ }^{1} \mathrm{H}-\mathrm{NMR}$ spectrum of HACHEMS showed clear peaks at 5.33 ppm that corresponded to CHEMS, and the characteristic signals were of HA (1.76, 4.44 and $7.43 \mathrm{ppm})$, indicating that HACHEMS was successfully synthesized. HA-CHEMS nanoparticles were prepared using the solvent-exchange method to dropwise the HA-CHEMS solution in DMSO to PBS. HA-CHEMS-Cur, HA-CHEMS-TPGS and HACHEMS-Cur-TPGS NPs were prepared using the same method. In order to optimize the drug loading of HACHEMS-Cur-TPGS NPs, we investigated the influence of TPGS content on particle size (PS) and drug loading (DL), with the results showing that the increased addition of TPGS could correspondingly increase DL. However,
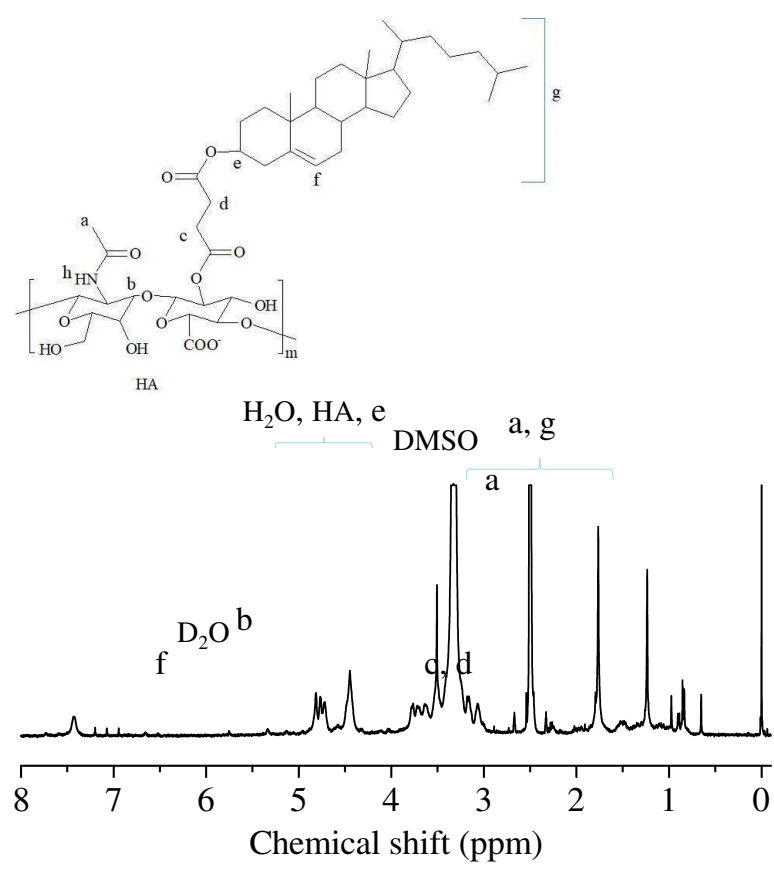

Figure $2{ }^{~} \mathrm{H}$ NMR spectrum $\left(400 \mathrm{MHz}, \mathrm{D}_{2} \mathrm{O} / \mathrm{DMSO}-\mathrm{d} 6\right)$ of $\mathrm{HA}-\mathrm{g}-\mathrm{CHEMS}$. after a certain threshold, excess TPGS obviously increased the particle size but decreased DL. According to the results of the PS and DL of NPs, a HA-CHEMS copolymer and TPGS conjugate ratio of 10:1 (w/w) were determined to be optimal, leading to a DL rate of $8.2 \%$ and a corresponding particle size of $144 \mathrm{~nm}$.

As measured by a dynamic light scattering (DLS) assay, the hydrodynamic diameter of HA-CHEMS-CurTPGS nanoparticles was $144 \mathrm{~nm}$, which was similar to the size of HA-CHEMS NPs (Figure 3A). Moreover, the hydrodynamic diameters of HA-CHEMS-Cur and HACHEMS-TPGS NPs were slight larger than that of the HA-CHEMS nanoparticles. The transmission electron microscopy (TEM) picture showed that HA-CHEMSCur-TPGS NPs had a spherical structure with an average size of $98 \mathrm{~nm}$, which was close to the DLS data (Figure 3B). Moreover, the size estimated from TEM was slightly smaller than that obtained from DLS in an aqueous phase, which might be attributed to the shrinkage of the hydrophilic shell during the air-drying process in TEM sample preparation and the system error resulting from the determination principles between DLS (hydrated radius) and TEM.

Remarkably, HA-CHEMS-Cur-TPGS NPs also exhibited good colloidal stability in the PBS with little size change for over 1 week (Figure 3C), which probably was a result of strong interaction between cholesterol molecules and negative zeta potentials $(-20.14 \pm 1.12 \mathrm{mV})$ from the ionized carboxylic group of HA in the shell. In addition, the HA-CHEMS-Cur NPs also exhibited comparative negative zeta potentials $(-21.25 \pm 1.66 \mathrm{mV})$ with the HACHEMS-Cur-TPGS NPs.

The entrapment efficiency and drug loading of HACHEMS-Cur-TPGS NPs were determined using HPLC up to $84.0 \pm 5.0 \%$ and $8.2 \%$. To investigate the in vitro release behavior of curcumin, HA-CHEMS-Cur-TPGS NPs were dialyzed separately in the $\mathrm{PBS}$ at $\mathrm{pH}$ 5.0, 6.5, and 7.4. As shown in Figure 3D, the $50.5 \pm 2.4 \%$ curcumin was released from HA-CHEMS-Cur-TPGS NPs at $\mathrm{pH} 7.4$ within $24 \mathrm{~h}$, showing a sustained release behavior. The accumulative release at $\mathrm{pH} 7.4$ was significantly lower than that at $\mathrm{pH} 6.5$ $(75.8 \pm 2.1 \%)$ and $\mathrm{pH} 5.0(80.2 \pm 1.5 \%)$. The fast release of curcumin at low $\mathrm{pH}$ is likely due to the $\mathrm{pH}$ sensitivity of cholesteryl hemisuccinate in HA-CHEMS. ${ }^{45}$ Cholesteryl hemisuccinate (CHEMS) synthesized by succinic acid esterified to the L-hydroxyl group of cholesterol is an acidic cholesterol ester that can self-assemble into bilayers in neutral or basic medium. In acidic condition, CHEMS undergoes a phase 

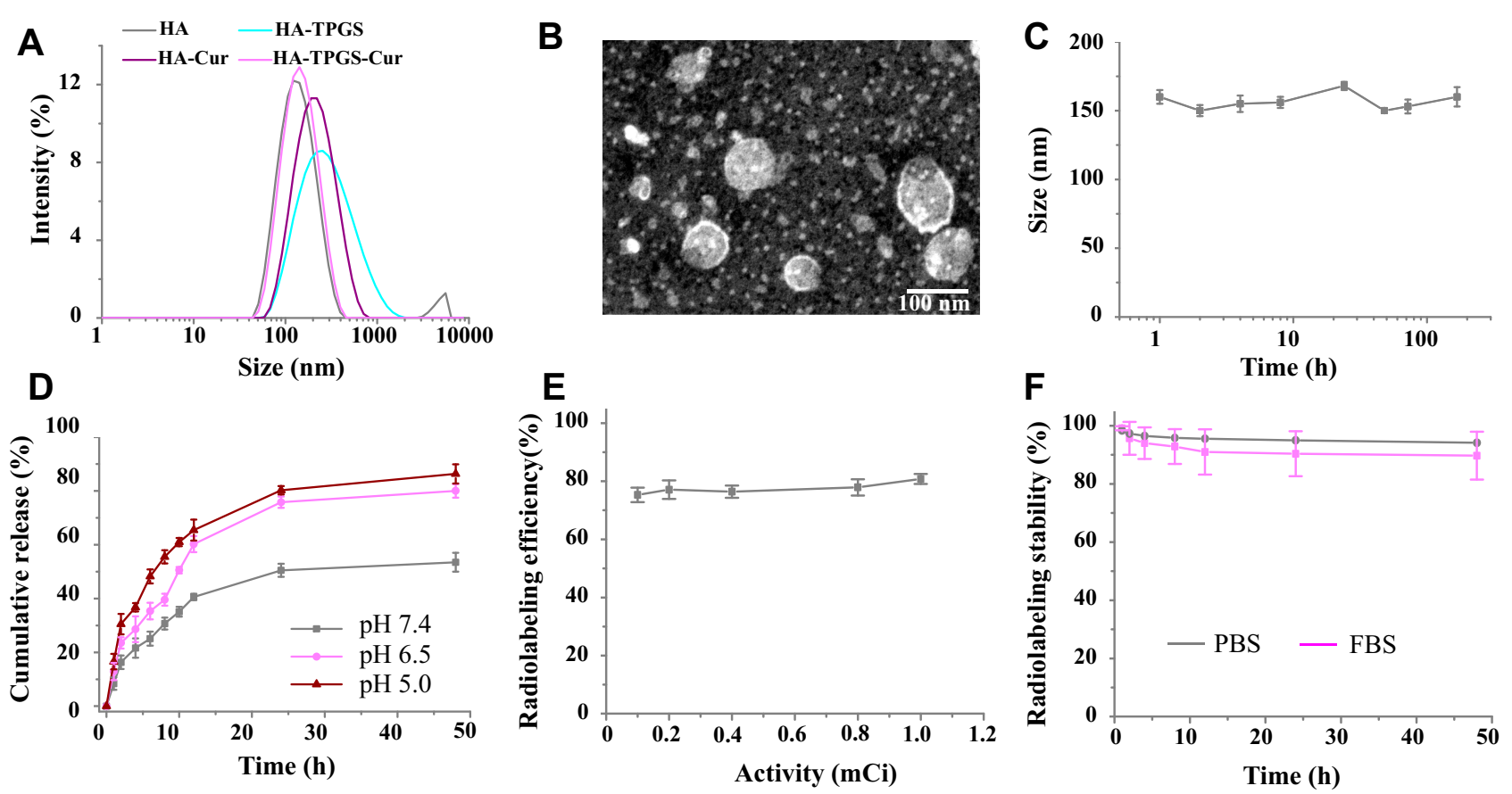

Figure 3 Characterization of nanoparticles: (A) Size and distribution as determined by DLS. (B) Morphology of HA-CHEMS-Cur-TPGS NPs as measured by TEM. (C) Colloidal stability at a concentration of $\mathrm{I} \mathrm{mg} / \mathrm{mL}$ in PBS. (D) Release of curcumin at a $\mathrm{PH}$ of 5.0, 6.5, and 7.4. (E) The correlation between the radiolabeling efficiency and added activity of ${ }^{99 \mathrm{~m}} \mathrm{Tc}$. (F) The radiostability of ${ }^{99 \mathrm{~m}} \mathrm{Tc}$-HA-CHEMS-Cur-TPGS NPs in the PBS and $10 \%$ FBS at $37{ }^{\circ} \mathrm{C}(\mathrm{n}=3)$.

transformation from the stable lamellar phase at a neutral $\mathrm{pH}$ to the unstable inverted hexagonal phase as a result of the protonation of its acidic head group. ${ }^{45,46}$ This suggests that once the HA-CHEMS-Cur-TPGS NPs internalized into tumor cells, because of CHEMS, the HA-CHEMS would be hydrolyzed in a lower $\mathrm{pH}$ environment of lysosomes (pH5.0), resulting in rapid drug release. In contrast, under the physiological condition ( $\mathrm{pH} 7.4)$, the drug was released slowly from the stable NPs.

The radioactive metal ${ }^{99 \mathrm{~m}} \mathrm{Tc}\left(\mathrm{t}_{1 / 2}=6 \mathrm{~h}, \mathrm{E} \gamma=173 \mathrm{keV}\right)$ emits gamma-rays, which can be detected by microSPECT. Moreover, metal ions can bind to the carboxyl group of HA and form a stable compound, which may be suitable for ${ }^{99 \mathrm{~m}} \mathrm{Tc}$ radiolabeling. To radiolabel HACHEMS-Cur-TPGS NPs, $\mathrm{SnCl}_{2}$ was used as a reducing agent and added to ${ }^{99 \mathrm{~m}} \mathrm{TcO}_{4}{ }^{-}$, which eluted from the ${ }^{99} \mathrm{Mo}-{ }^{99 \mathrm{~m}} \mathrm{Tc}$ generator. A radiolabeling efficiency up to $80.8 \pm 1.7 \%$ was achieved, as determined by ultrafiltration. Besides the carboxyl group, two close ester groups also could be used for ${ }^{99 \mathrm{~m}} \mathrm{Tc}$ radiolabeling. Tesan et al reported that ${ }^{99 \mathrm{~m}} \mathrm{Tc}$ radiolabeled TPGS micelles and displayed excellent radiostability in vivo. ${ }^{47}$ Hence, the radiolabeling of HA-CHEMS-Cur-TPGS NPs could be explained by the complexation of ${ }^{99 \mathrm{~m}} \mathrm{Tc}$ and carboxyl group or two close ester groups. The successful radiolabeling of ${ }^{99 \mathrm{~m}} \mathrm{Tc}$ was found to provide an opportunity for radionuclide ${ }^{188} \mathrm{Re}$ to be used as internal radionuclide therapy. ${ }^{48,49}$ To optimize the ${ }^{99 \mathrm{~m}} \mathrm{Tc}$ labeling, varied activity of ${ }^{99 \mathrm{~m}} \mathrm{Tc}$ was radiolabeled with a fixed HA-CHEMS-Cur-TPGS NPs concentration. The radiolabeling efficiency was similar when varying the activity of ${ }^{99 \mathrm{~m}} \mathrm{Tc}$ from $0.1 \mathrm{mCi}$ to $1 \mathrm{mCi}$, which meant that we could radiolabel enough ${ }^{99 \mathrm{~m}} \mathrm{Tc}$ for clinical application (Figure 3E). This potentially explains the low chemical amount of ${ }^{99 \mathrm{~m}} \mathrm{Tc}$ used for radiolabeling (1 $\mathrm{mCi}$ corresponded to $1.9 \times 10^{-11} \mathrm{~mol}$ ) is sufficient. Maintaining the drug within the nanoparticles for a long time in blood is the prerequisite for drug accumulation in tumor regions and antitumor efficiency. The stability of ${ }^{99} \mathrm{~m}$ Tc radiolabeling HA-CHEMS-Cur-TPGS nanoparticles in vitro was investigated by incubation ${ }^{99 \mathrm{~m}} \mathrm{Tc}-\mathrm{HA}-$ CHEMS-Cur-TPGS NPs with the PBS and 10\% FBS at $37{ }^{\circ} \mathrm{C}$ with $48 \mathrm{~h}$, respectively. As shown in Figure 3F, less than $10 \%$ freedom ${ }^{99 \mathrm{~m}} \mathrm{Tc}$ was detected in the PBS and $10 \%$ FBS solution by measuring the radioactivity of freedom ${ }^{99 \mathrm{~m}} \mathrm{Tc}$, suggesting a good radiostability for further in vivo study.

\section{In vitro Cytotoxicity Assay}

The potential cytotoxicity of HA-CHEMS NPs, curcumin, HA-CHEMS-Cur NPs, HA-CHEMS-TPGS NPs and HA- 
CHEMS-Cur-TPGS NPs was evaluated in 4T1 cells using the methyl thiazolyl tetrazolium (MTT) assay. The results showed that no obvious toxicity of HA-CHEMS NPs was observed in 4T1 cells up to a concentration of $1 \mathrm{mg} / \mathrm{mL}$ (Figure 4A). Figure 4B shows the toxic effect of free curcumin, HA-CHEMS-Cur NPs, HA-CHEMS-TPGS NPs and HA-CHEMS-Cur-TPGS NPs against 4T1 cells for $24 \mathrm{~h}$. All groups displayed a concentration-dependent toxicity of curcumin and TPGS. Furthermore, the IC50 (concentrations of 50\% 4T1 cells growth inhibition) values of curcumin, HA-CHEMS-Cur NPs, HA-CHEMS-TPGS NPs and HA-CHEMS-Cur-TPGS NPs were 77, 58, 103 and $38 \mu \mathrm{g} / \mathrm{mL}$, respectively. Remarkably, HA-CHEMSCur-TPGS NPs showed the highest toxicity for 4T1 cells compared to free curcumin, HA-CHEMS-Cur NPs, and HA-CHEMS-TPGS NPs, which might be because of the elevated intracellular drug level caused by rapid drug release from nanoparticles after the internalization of HA-CHEMS-Cur-TPGS nanoparticles and the synergistic effect between HA-CHEMS-Cur with TPGS. The combination index (CI) value of HA-CHEMS-Cur and TPGS was calculated as 0.79 . Drugs have moderate synergism when the CI value is between 0.6 and 0.8 . These results indicated that curcumin, HA-CHEMS-Cur NPs and HACHEMS-Cur-TPGS NPs can inhibit 4T1 cells, and TPGS can enhance antitumor efficiency.

\section{In vivo Imaging and Pharmacokinetics}

MicroSPECT imaging of radiolabeled ${ }^{99 \mathrm{~m}} \mathrm{Tc}$ was employed to record the in vivo biodistribution and evaluate the tumor-targeting ability of HA-CHEMS-Cur-TPGS NPs in 4T1-tumor-bearing BALB/c mice. The mice that injected free HA $1 \mathrm{~h}$ earlier and followed ${ }^{99 \mathrm{~m}} \mathrm{Tc}-\mathrm{HA}-$ CHEMS-Cur-TPGS NP injection were regarded as the control. MicroSPECT images showed the biodistribution of ${ }^{99 m}$ Tc-HA-CHEMS-Cur-TPGS NPs and control group in $4 \mathrm{~T} 1$ tumor bearing mice within $24 \mathrm{~h}$ (Figure 5A and B). The radioactive intensity at the tumor sites was obviously higher in the ${ }^{99 \mathrm{~m}}$ Tc-HA-CHEMS-Cur-TPGS NPs group than in the control. The tumor uptake of ${ }^{99 \mathrm{~m}} \mathrm{Tc}-\mathrm{HA}-$ CHEMS-Cur-TPGS NPs peaked at $4 \mathrm{~h}$ post-injection, indicating that HA can actively target to tumor tissue. Meanwhile, no radioactive signal was found in the thyroid, suggesting that the complexation of ${ }^{99} \mathrm{~m} \mathrm{Tc}$ and HACHEMS-Cur-TPGS is stable in vivo, the conclusion according to that free ${ }^{99 \mathrm{~m}} \mathrm{Tc}$ can be oxidized to ${ }^{99 \mathrm{~m}} \mathrm{TcO}_{4}{ }^{-}$ and accumulate in the thyroid. ${ }^{50,51}$ Quantitative analysis of microSPECT images showed that the maximum radioactivity intensity of tumor tissue was $4.85 \pm 0.24 \% \mathrm{ID} / \mathrm{g}$ at $4 \mathrm{~h}$ post-injection but was less than $1 \% \mathrm{ID} / \mathrm{g}$ in the control group (Figure 5C). Notably, there was more than $3 \% \mathrm{ID} / \mathrm{g}$ of the radioactivity retained in tumor tissue at $8 \mathrm{~h}$ postinjection. This result indicated that the nanoparticles can accumulate in a tumor via the enhanced permeation retention (EPR) effect or nanomaterials-induced endothelial leakiness (NanoEL). ${ }^{52-59}$ Moreover, a high concentration with prolonged retention of the nanoparticles can provide more drug release to tumor cells and potentially induce more cell death.

In order to evaluate the plasma pharmacokinetics of HA-CHEMS-Cur-TPGS NPs, healthy mice were intravenously injected with ${ }^{99 m}$ Tc-HA-CHEMS-Cur-TPGS NPs. The blood sample was collected from the retinal vein for radioactivity assay by $\gamma$ counter at different post-injection times. The pharmacokinetic analyses demonstrated that ${ }^{99 m}$ Tc-HA-CHEMS-Cur-TPGS NPs exhibited a prolonged blood circulation time $\left(\mathrm{t}_{1 / 2, \beta}=7.8 \mathrm{~h}\right)$ (Figure 5D). Jin et al found that the half-life of free curcumin was only
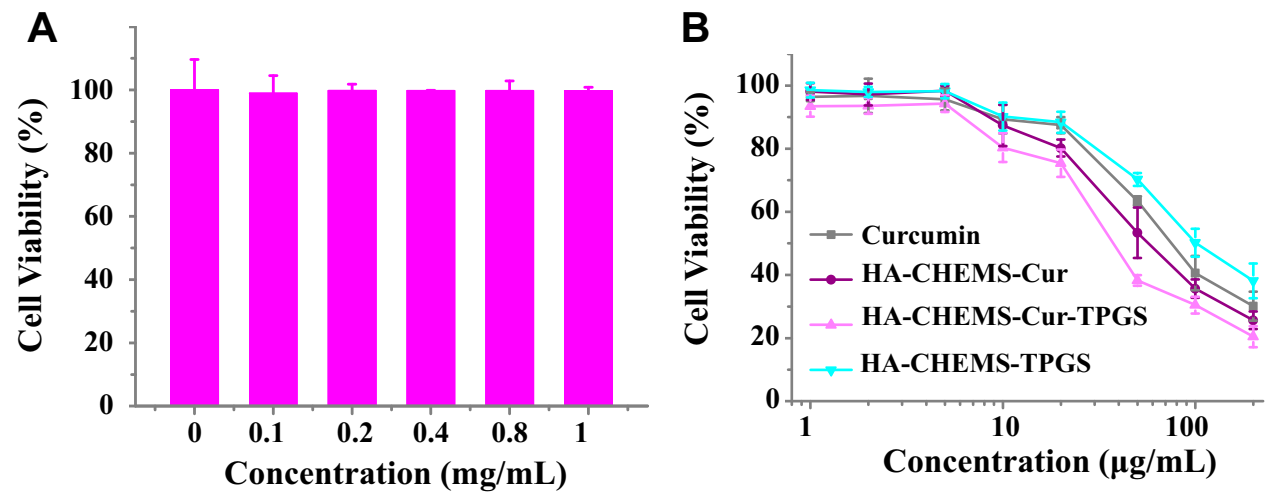

Figure 4 MTT assays. (A) Viability of 4TI cell incubated with HA-CHEMS nanoparticles, with concentrations varying from 0 to I mg/mL. (B) Viability of 4 TI cell incubated with curcumin, HA-CHEMS-Cur NPs, HA-CHEMS-TPGS NPs and HA-CHEMS-Cur-TPGS NPs. 


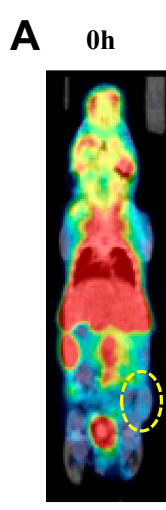

$\mathbf{2 h}$
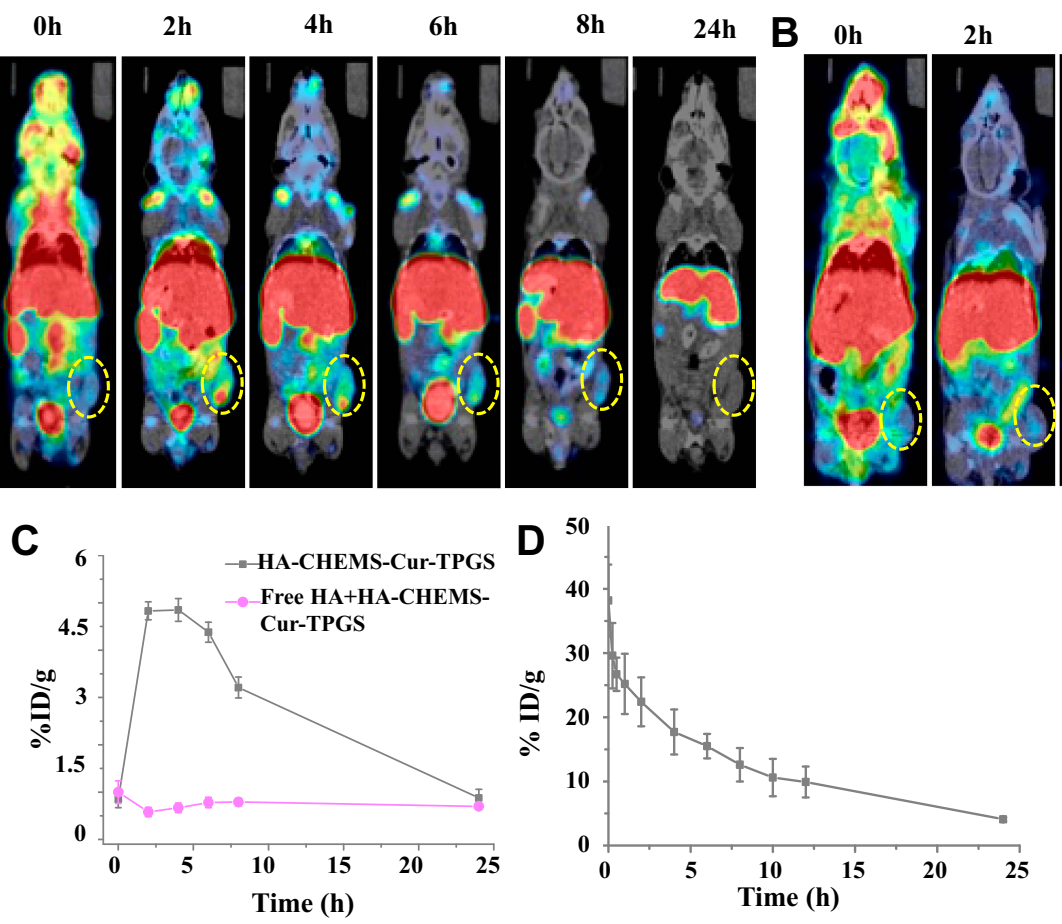
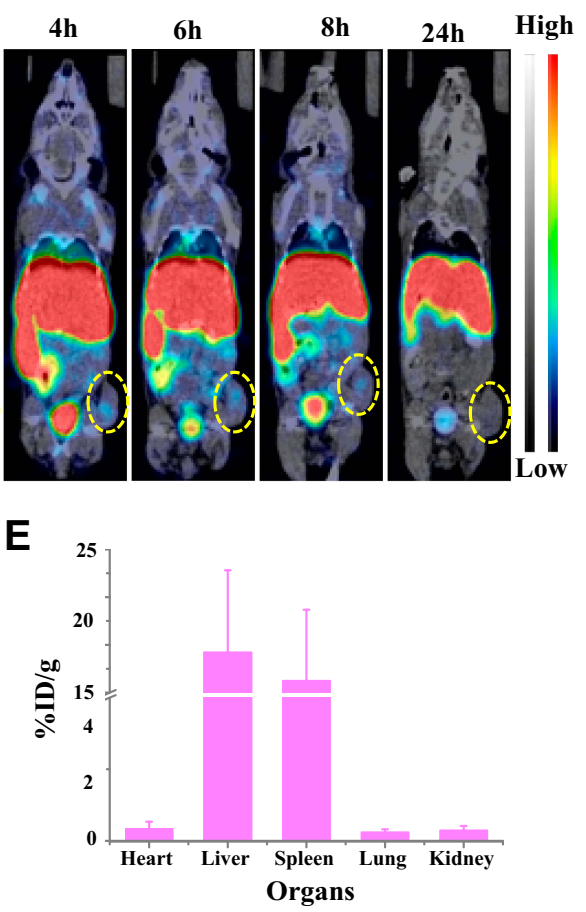

Figure 5 In vivo biodistribution of HA-CHEMS-Cur-TPGS NPs in 4TI-tumor-bearing BALB/c mice. MicroSPECT/CT of (A) ${ }^{99 m}$ Tc- HA-CHEMS-Cur-TPGS NPs and (B) injection of free HA I h earlier and followed by ${ }^{99 \mathrm{~m}} \mathrm{Tc}-\mathrm{HA}-\mathrm{CHEMS}-\mathrm{Cur}-\mathrm{TPGS}$ NPs injection at $0,2,4,6,8$ and $24 \mathrm{~h}$ post-injection in mice following the i.v. injection. (C) Percentage of tumor accumulation of ${ }^{99 \mathrm{~m}}$ Tc-HA-CHEMS-Cur-TPGS NPs after intravenous injection. (D) Blood circulation of ${ }^{99 \mathrm{~m}}$ Tc-HA-CHEMS-Cur-TPGS NPs at $24 \mathrm{~h}$ postinjection. (E) Biodistribution of major organs measured by $\gamma$-counter at $24 \mathrm{~h}$ post-injection.

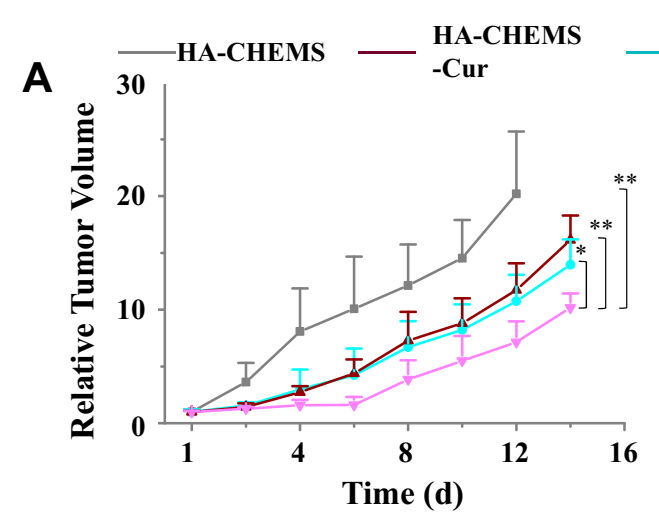

HA-CHEMS — HA-CHEMS
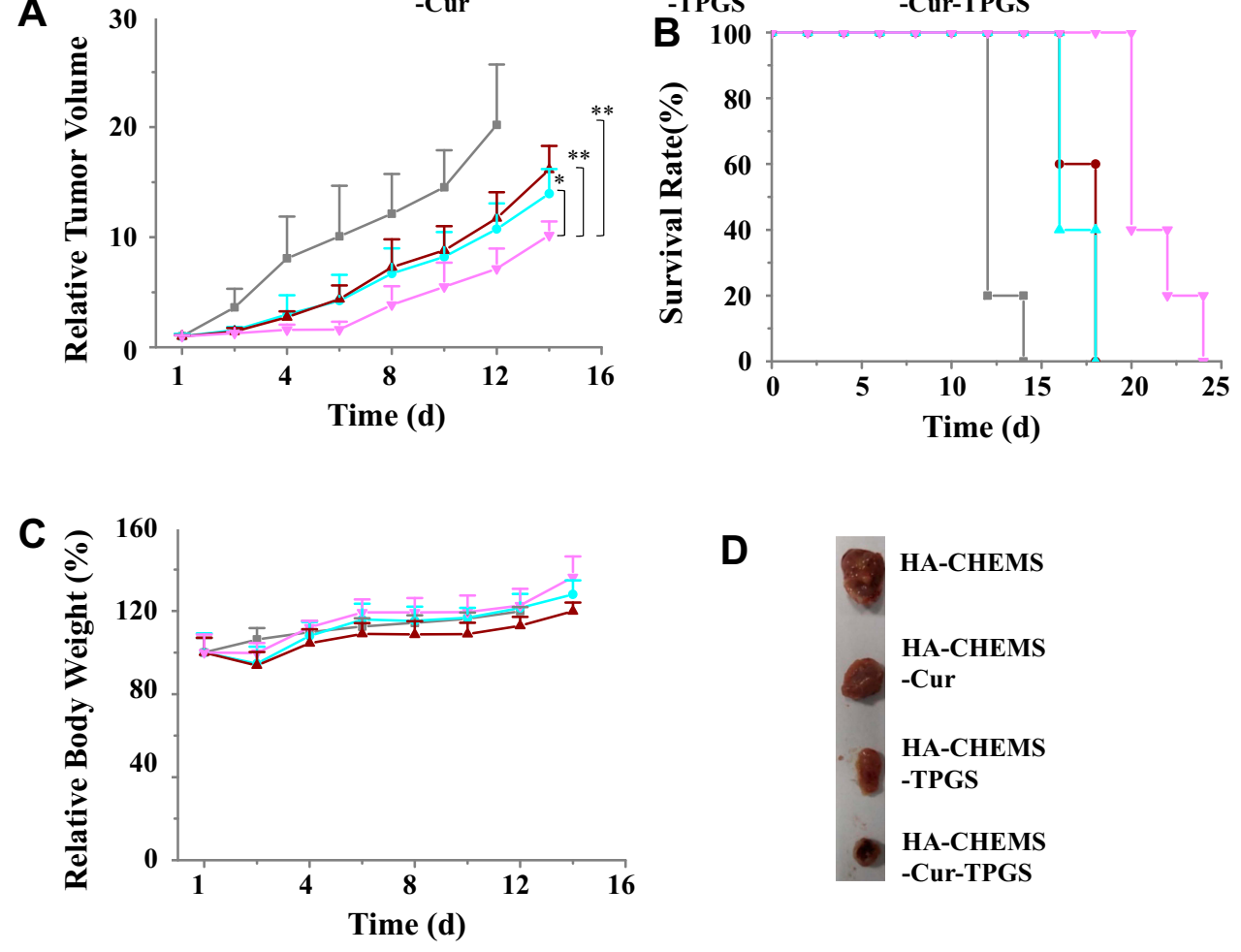

Figure 6 In vivo antitumor performance of nanoparticles in 4TI-tumor-bearing BALB/c mice. HA-CHEMS-Cur-TPGS NPs were given on days 0 , 2, 4, 6 and 8 with a concentration of $50 \mathrm{mg} / \mathrm{kg}$. (A) $4 \mathrm{TI}$ tumor growth rate. Statistical analysis: ${ }^{*} \mathrm{p}<0.05$, ${ }^{* *} \mathrm{p}<0.01$. (B) Survival curves of mice after 24 days. (C) Body weight changes of mice. (D) Photographs of tumor blocks collected from different treatments groups on day 14. 
8 minutes. $^{60}$ Hence, the ${ }^{99 \mathrm{~m}}$ Tc-HA-CHEMS-Cur-TPGS NPs apparently extended the circulation half-life of curcumin from several minutes to several hours. Further, we studied the biodistribution of ${ }^{99 \mathrm{~m}} \mathrm{Tc}-\mathrm{HA}-\mathrm{CHEMS}-\mathrm{Cur}-$ TPGS NPs in healthy mice. Major organs were excised at $24 \mathrm{~h}$ post-injection by intravenous injection via the tail vein. Twenty-four hours post-injection, the main distribution of ${ }^{99}$ Tc-HA-CHEMS-Cur-TPGS NPs settled more in the liver $(19.21 \pm 8.6 \% \mathrm{ID} / \mathrm{g})$ and spleen $(16.24 \pm 7.4 \% \mathrm{ID} / \mathrm{g})$ compared to other organs such as the heart $(0.42 \pm 0.25 \% \mathrm{ID} / \mathrm{g})$, lung $(0.3 \pm 0.1 \% \mathrm{ID} / \mathrm{g})$, and kidney $(0.37 \pm 0.15 \% \mathrm{ID} / \mathrm{g})$ (Figure 5E). Generally, the nanoparticles were captured by the reticuloendothelial system which is concentrated mainly in the liver and spleen. ${ }^{61,62}$ However, the total activity of ${ }^{99 m}$ Tc-HA-CHEMS-Cur-TPGS NPS decreased fast, and there was only $20.5 \pm 3.1$ ID $\%$ left in the mice $24 \mathrm{~h}$ post-
HA-CHEMS HA-CHEMS HA-CHEMS HA-CHEMS

A
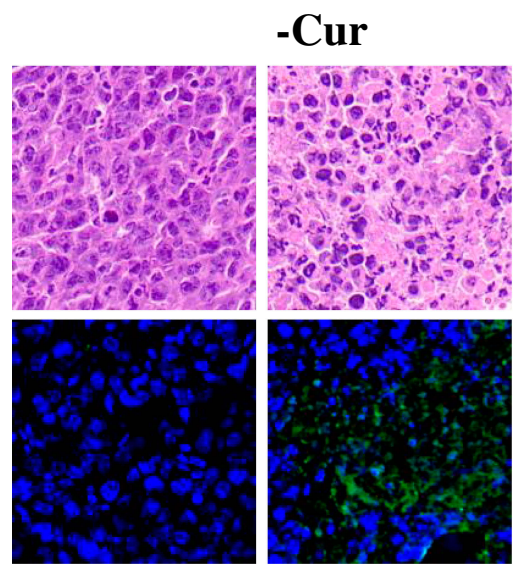

Heart

B
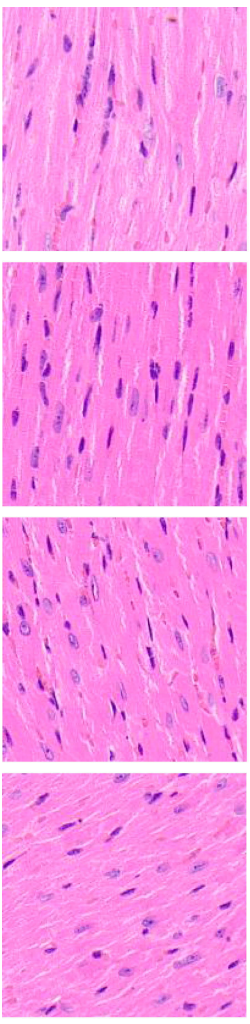
-TPGS
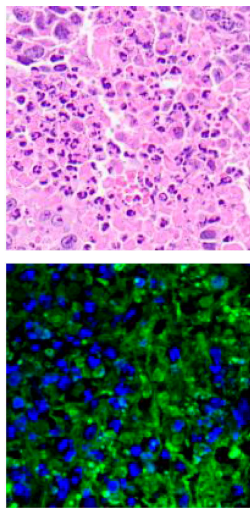

Liver
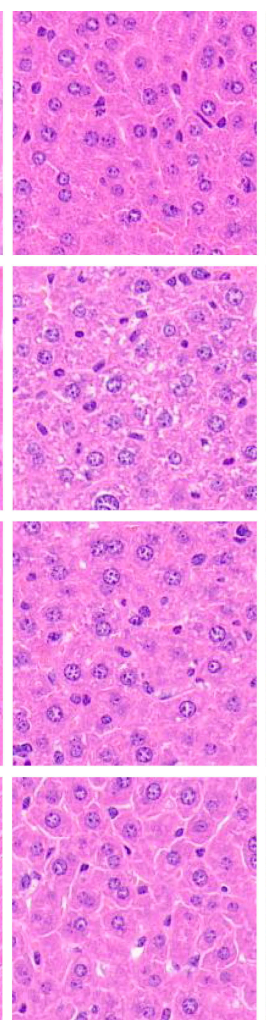

Spleen

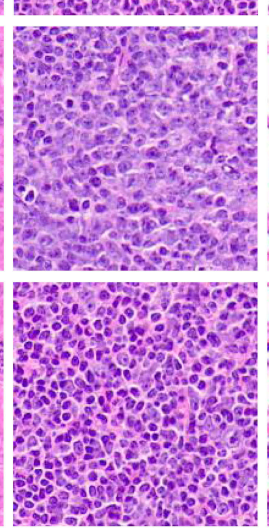

-Cur-TPGS
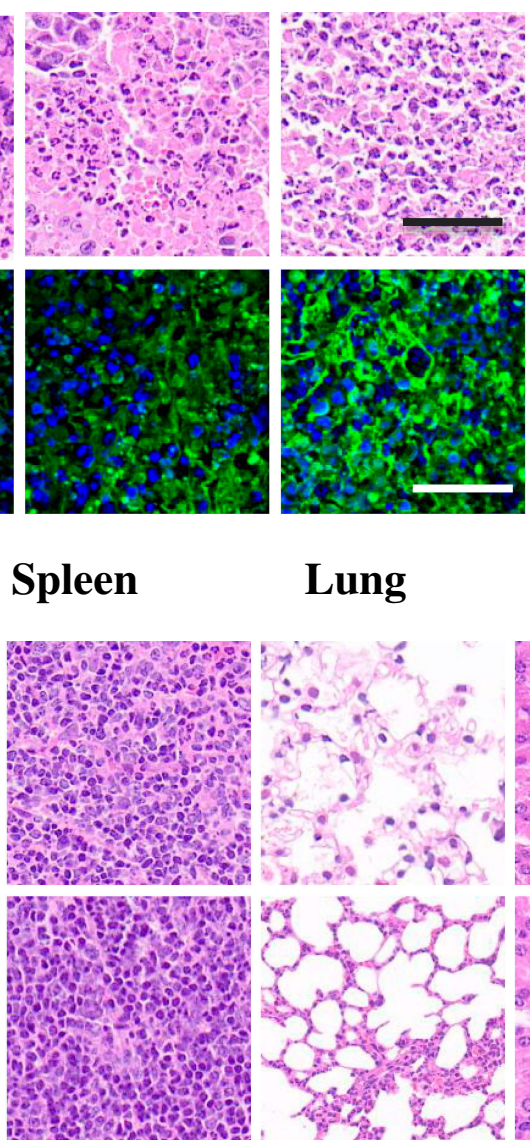

Lung

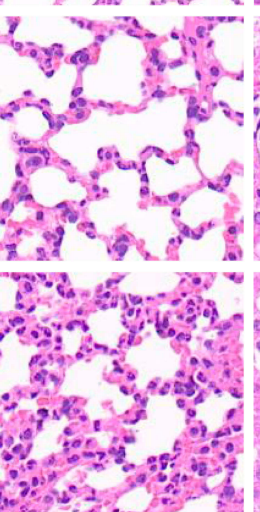

\section{HE}

\section{TUNEL}

Kidney
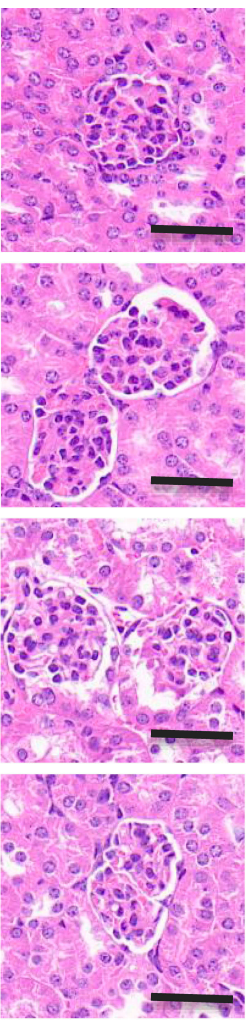

HA-CHEMS

-Cur

HA-CHEMS

HA-CHEMS -TPGS

HA-CHEMS -Cur-TPGS

Figure 7 H\&E and TUNEL staining assays of tumor $(\mathbf{A})$ and health organs $(\mathbf{B})$ in different treatment groups. All the scale bars present $100 \mu \mathrm{m}$. 
injection, indicating that ${ }^{99 \mathrm{~m}} \mathrm{Tc}-\mathrm{HA}-\mathrm{CHEMS}-\mathrm{Cur}$-TPGS NPs excretes quickly in normal organs and that the rapid metabolism of HA-CHEMS-Cur-TPGS NPs can decrease cytotoxicity to the health tissue in vivo.

\section{In vivo Antitumor Efficacy}

After assessing the targeting ability of HA-CHEMS-CurTPGS NPs, the in vivo antitumor efficiency and systemic toxicity of HA-CHEMS-Cur-TPGS NPs were evaluated in 4T1-tumor-bearing mice. The tumor volumes and body weights of 4T1- tumor-bearing mice were measured after intravenous administration of HA-CHEMS NPs (control), HA-CHEMS-TPGS NPs and two curcumin formulations at a dose of $50 \mathrm{mg} / \mathrm{kg}$. The HA-CHEMS group showed the lowest tumor inhibition effect, with a mean tumor size of $996.8 \pm 262.3 \mathrm{~mm}^{3}$ at day 12. Unlike HA-CHEMS NPs, the HA-CHEMS-TPGS NPs showed a relatively higher effect of tumor reduction, with a mean tumor size of 619.5 $\pm 134.4 \mathrm{~mm}^{3}$ at day 12 . Moreover, a recent study showed that TPGS could reverse multidrug resistance by altering the cell's membrane and improving cellular uptake. ${ }^{63-65}$ HA-CHEMS-Cur-TPGS NPs exhibited the highest tumor growth inhibition; the mean tumor size was only 435.5 $\pm 87.3 \mathrm{~mm}^{3}$ at day 12. After the 12th day, the growth of tumors in all groups was faster than the growth during the treatment since we stopped injection of nanoparticles on the 10th day. The biodistribution study demonstrated that the retention of HA-CHEMS-Cur-TPGS NPs was only 0.88 $\pm 0.18 \mathrm{ID} \% / \mathrm{g}$ in the tumor after $24 \mathrm{~h}$. The uncontrolled tumor growth could be due to the depletion of nanoparticles. Hence, HA-CHEMS-Cur-TPGS NPs exhibited significant inhibition of tumor growth compared to HA-CHEMS-Cur NPs, and HA-CHEMS-TPGS NPs (Figure 6A). The antitumor efficacy results indicated that TPGS can enhance the curcumin antitumor efficacy in vivo. In addition, KaplanMeier survival curves showed that the treatment of HACHEMS-Cur-TPGS NPs resulted in a significantly longer median survival time than the other three groups (Figure 6B). Moreover, all treated groups of mice displayed no severe weight loss, indicating that nanoparticles have little systematic toxicity (Figure 6C). Figure 6D shows the tumor blocks at 14 days after treatment, and the results suggested that HA-CHEMS-Cur-TPGS NPs have better antitumor efficiency than HA-CHEMS-Cur NPs.

To further evaluate antitumor efficiency and in vivo cytotoxicity, tumor and major organs were sliced for histological analysis by using $\mathrm{H} \& \mathrm{E}$ and TUNEL staining. After staining with H\&E, the HA-CHEMS-Cur-TPGS NPs group showed more necrosis in the tumor site compared to the HA-CHEMS NPs, HA-CHEMS-Cur NPs and HA-CHEMS-TPGS NPs groups (Figure 7A). Furthermore, the TUNEL assay revealed that the HA-CHEMS-Cur-TPGS NPs group induced more apoptosis of tumor cells (Figure 7A). All the groups showed little damage in major organs (Figure 7B). Cumulatively, the results indicated that HA-CHEMS-Cur-TPGS NPs are an excellent antitumor nanomedicine for breast cancer with enhanced tumor-specific accumulation, improved antitumor efficiency, and low side effects.

\section{Conclusion}

In this study, we successfully prepared ${ }^{99 \mathrm{~m}}$ Tc-HA-CHEMSCur-TPGS NPs for synergistic chemotherapy and conducted nuclear imaging for breast cancer in mice. The HA-CHEMS-Cur-TPGS NPs exhibited a uniform particle size distribution, excellent in vitro stability and high radiolabeling efficiency with good radiostability. Furthermore, the in vivo SPECT imaging demonstrated that ${ }^{99 \mathrm{~m}} \mathrm{Tc}-\mathrm{HA}-$ CHEMS-Cur-TPGS NPs could actively target to breast cancer in mice. The retention of ${ }^{99 \mathrm{~m}} \mathrm{Tc}-\mathrm{HA}-\mathrm{CHEMS}-\mathrm{Cur}-$ TPGS NPs was higher than $3 \% \mathrm{ID} / \mathrm{g}$ until $8 \mathrm{~h}$ post-injection, with fast total body excretion. The antitumor inhibition results confirmed that the antitumor efficiency of curcumin was elevated with the help of TPGS without obviously toxicity compared with HA-CHEMS-Cur NPs. The findings indicated that ${ }^{99 m}$ Tc-HA-CHEMS-Cur-TPGS NPs with excellent CD44 active targeting, effective tumor inhibition, and nuclear imaging can serve as a novel platform for breast cancer theranostics.

\section{Acknowledgments}

This work was supported by the National Natural Science Foundation of China (No. 81703709, 81703425), the Project Funds from Science and Technology Council of Liaoning Province (No. 2019-ZD-0433) and China Postdoctoral Science Foundation Funded Project (No. 2018M641716).

\section{Disclosure}

Fen Chen is employed by Zhejiang Jingxin Pharmaceutical Co., Ltd. The authors report no other conflicts of interest in this work.

\section{References}

1. Bray F, Ferlay J, Soerjomataram I, Siegel RL, Torre LA, Jemal A. Global cancer statistics 2018: GLOBOCAN estimates of incidence and mortality worldwide for 36 cancers in 185 countries. CA Cancer J Clin. 2018;68(6):394-424. doi:10.3322/caac.21492 
2. Salehi B, Stojanovic-Radic Z, Matejic J, et al. The therapeutic potential of curcumin: a review of clinical trials. Eur J Med Chem. 2019;163:527-545. doi:10.1016/j.ejmech.2018.12.016

3. Nelson KM, Dahlin JL, Bisson J, Graham J, Pauli GF, Walters MA The Essential medicinal chemistry of curcumin. J Med Chem. 2017;60(5):1620-1637. doi:10.1021/acs.jmedchem.6b00975

4. Batra H, Pawar S, Bahl D. Curcumin in combination with anti-cancer drugs: a nanomedicine review. Pharmacol Res. 2019;139:91-105. doi:10.1016/j.phrs.2018.11.005

5. Barati N, Momtazi-Borojeni AA, Majeed M, Sahebkar A. Potential therapeutic effects of curcumin in gastric cancer. J Cell Physiol. 2019;234(3):2317-2328. doi:10.1002/jcp.27229

6. Hesari A, Azizian M, Sheikhi A, et al. Chemopreventive and therapeutic potential of curcumin in esophageal cancer: current and future status. Int J Cancer. 2019;144(6):1215-1226. doi:10.1002/ijc.31947

7. Anand P, Kunnumakkara A, Newman RA, Aggarwal BB. Bioavailability of curcumin: problems and promises. Mol Pharm. 2007;4(6):807-818. doi:10.1021/mp700113r

8. Feng T, Wei Y, Lee RJ, Zhao L. Liposomal curcumin and its application in cancer. Int J Nanomedicine. 2017;12:6027-6044. doi:10.2147/ IJN.S132434

9. Liu Y, Huang P, Hou X, et al. Hybrid curcumin-phospholipid complex-near-infrared dye oral drug delivery system to inhibit lung metastasis of breast cancer. Int J Nanomedicine. 2019;14:33113330. doi:10.2147/IJN.S200847

10. Ramasamy T, Ruttala HB, Gupta B, et al. Smart chemistry-based nanosized drug delivery systems for systemic applications: a comprehensive review. $J$ Control Release. 2017;258:226-253. doi:10.1016/j.jconrel.2017.04.043

11. Pattni BS, Chupin VV, Torchilin VP. New developments in liposomal drug delivery. Chem Rev. 2015;115(19):10938-10966. doi:10.1021/ acs.chemrev.5b00046

12. Silva CO, Pinho JO, Lopes JM, Almeida AJ, Gaspar MM, Reis C. Current trends in cancer nanotheranostics: metallic, polymeric, and lipid-based systems. Pharmaceutics. 2019;11(1):22. doi:10.3390/ pharmaceutics 11010022

13. Liu Y, Bhattarai P, Dai Z, Chen X. Photothermal therapy and photoacoustic imaging via nanotheranostics in fighting cancer. Chem Soc Rev. 2019;48(7):2053-2108.

14. Vankayala R, Hwang KC. Near-infrared-light-activatable nanomaterial-mediated phototheranostic nanomedicines: an emerging paradigm for cancer treatment. Adv Mater. 2018;30(23):e1706320. doi:10.1002/ adma.201706320

15. Zhou Y, Peng Z, Seven ES, Leblanc RM. Crossing the blood-brain barrier with nanoparticles. J Control Release. 2018;270:290-303. doi:10.1016/j.jconrel.2017.12.015

16. Gai S, Yang G, Yang P, et al. Recent advances in functional nanomaterials for light-triggered cancer therapy. Nano Today. 2018;19:146-187. doi:10.1016/j.nantod.2018.02.010

17. Kamel AE, Fadel M, Louis D. Curcumin-loaded nanostructured lipid carriers prepared using peceol and olive oil in photodynamic therapy: development and application in breast cancer cell line. Int $J$ Nanomedicine. 2019;14:5073-5085. doi:10.2147/IJN.S210484

18. Zhao S, Ma L, Cao C, Yu Q, Chen L, Liu J. Curcumin-loaded redox response of self-assembled micelles for enhanced antitumor and antiinflammation efficacy. Int J Nanomedicine. 2017;12:2489-2504. doi:10.2147/IJN.S123190

19. Mura S, Nicolas J, Couvreur P. Stimuli-responsive nanocarriers for drug delivery. Nat Mater. 2013;12(11):991-1003. doi:10.1038/ nmat3776

20. Ekladious I, Colson YL, Grinstaff MW. Polymer-drug conjugate therapeutics: advances, insights and prospects. Nat Rev Drug Discov. 2019;18(4):273-294.

21. Gao S, Tang G, Hua D, et al. Stimuli-responsive bio-based polymeric systems and their applications. J Mater Chem B. 2019;7(5):709-729. doi:10.1039/C8TB02491J
22. Hu YW, Du YZ, Liu N, et al. Selective redox-responsive drug release in tumor cells mediated by chitosan-based glycolipid-like nanocarrier. $J$ Control Release. 2015;206:91-100. doi:10.1016/j.jconrel.2015.03.018

23. Huang G, Huang H. Hyaluronic acid-based biopharmaceutical delivery and tumor-targeted drug delivery system. J Control Release. 2018;278:122-126. doi:10.1016/j.jconrel.2018.04.015

24. Chen C, Zhao S, Karnad A, Freeman JW. The biology and role of CD44 in cancer progression: therapeutic implications. J Hematol Oncol. 2018;11(1):64. doi:10.1186/s13045-018-0605-5

25. Misra S, Heldin P, Hascall VC, et al. Hyaluronan-CD44 interactions as potential targets for cancer therapy. FEBS J. 2011;278(9):14291443. doi:10.1111/j.1742-4658.2011.08071.x

26. Dosio F, Arpicco S, Stella B, Fattal E. Hyaluronic acid for anticancer drug and nucleic acid delivery. Adv Drug Deliv Rev. 2016;97:204236. doi:10.1016/j.addr.2015.11.011

27. Xi Y, Jiang T, Yu Y, et al. Dual targeting curcumin loaded alendronate-hyaluronan- octadecanoic acid micelles for improving osteosarcoma therapy. Int J Nanomedicine. 2019;14:6425-6437. doi:10.2147/ IJN.S211981

28. Su Z, Liu D, Chen L, et al. CD44-targeted magnetic nanoparticles kill head and neck squamous cell carcinoma stem cells in an alternating magnetic field. Int $J$ Nanomedicine. 2019;14:7549-7560. doi:10.2147/IJN.S215087

29. Hang C, Zou Y, Zhong Y, Zhong Z, Meng F. NIR and UV-responsive degradable hyaluronic acid nanogels for CD44-targeted and remotely triggered intracellular doxorubicin delivery. Colloids Surf B Biointerfaces. 2017;158:547-555. doi:10.1016/j.colsurfb.2017.07.041

30. Yang Z, Sun N, Cheng R, Zhao C, Liu J, Tian Z. Hybrid nanoparticles coated with hyaluronic acid lipoid for targeted co-delivery of paclitaxel and curcumin to synergistically eliminate breast cancer stem cells. $J$ Mater Chem B. 2017;5(33):6762-6775. doi:10.1039/C7TB01510K

31. Jeannot V, Gauche C, Mazzaferro S, et al. Anti-tumor efficacy of hyaluronan-based nanoparticles for the co-delivery of drugs in lung cancer. $J$ Control Release. 2018;275:117-128. doi:10.1016/j.jconrel.2018.02.024

32. Gu Z, Wang X, Cheng R, Cheng L, Zhong Z. Hyaluronic acid shell and disulfide-crosslinked core micelles for in vivo targeted delivery of bortezomib for the treatment of multiple myeloma. Acta Biomater. 2018;80:288-295. doi:10.1016/j.actbio.2018.09.022

33. Zhang Z, Tan S, Feng SS. Vitamin E TPGS as a molecular biomaterial for drug delivery. Biomaterials. 2012;33(19):4889-4906. doi:10.1016/j.biomaterials.2012.03.046

34. Yang C, Wu T, Qi Y, Zhang Z. Recent advances in the application of vitamin E TPGS for drug delivery. Theranostics. 2018;8(2):464-485. doi:10.7150/thno. 22711

35. Gorain B, Choudhury H, Pandey M, Kesharwani P. Paclitaxel loaded vitamin E-TPGS nanoparticles for cancer therapy. Mater Sci Eng C Mater Biol Appl. 2018;91:868-880. doi:10.1016/j.msec.2018.05.054

36. Kutty R, Tay C, Lim C, Feng S, Leong D. Anti-migratory and increased cytotoxic effects of novel dual drug-loaded complex hybrid micelles in triple negative breast cancer cells. Nano Res. 2015;8:2533-2547. doi:10.1007/s12274-015-0760-8

37. Kutty R, Chia S, Setyawati M, Muthu M, Feng S, Leong D. In vivo and ex vivo proofs of concept that cetuximab conjugated vitamin $\mathrm{E}$ TPGS micelles increases efficacy of delivered docetaxel against triple negative breast cancer. Biomaterials. 2015;63:58-69. doi:10.1016/j. biomaterials.2015.06.005

38. Tan G, Feng S, Leong D. The reduction of anti-cancer drug antagonism by the spatial protection of drugs with PLA-TPGS nanoparticles. Biomaterials. 2014;35:3044-3051. doi:10.1016/j.biomaterials.2013. 12.033

39. Boros E, Packard AB. Radioactive transition metals for imaging and therapy. Chem Rev. 2019;119(2):870-901. doi:10.1021/acs.chemrev. $8 \mathrm{~b} 00281$

40. Banerjee S, Pillai MR, Ramamoorthy N. Evolution of Tc-99m in diagnostic radiopharmaceuticals. Semin Nucl Med. 2001;4:260-277. doi:10.1053/snuc.2001.26205 
41. Laznicek M, Laznickova A, Cozikva D, Velebny V. Preclinical pharmacokinetics of radiolabelled hyaluronan. Pharmacol Rep. 2012;64:428-437. doi:10.1016/S1734-1140(12)70784-3

42. Polyak A, Hajdu I, Bodnar M, et al. (99m) Tc-labelled nanosystem as tumour imaging agent for SPECT and SPECT/CT modalities. Int $J$ Pharm. 2013;449(1-2):10-17. doi:10.1016/j.ijpharm.2013.03.049

43. Song S, Qi H, Xu J, et al. Hyaluronan-based nanocarriers with CD44overexpressed cancer cell targeting. Pharm Res. 2014;31(11):29883005. doi:10.1007/s11095-014-1393-4

44. Qhattal HSS, Hye T, Alali A, Liu X. Hyaluronan polymer length, grafting density, and surface poly (ethylene glycol) coating influence in vivo circulation and tumor targeting of hyaluronan grafted liposomes. ACS Nano. 2014;8:5423-5440. doi:10.1021/nn405839n

45. Hafez IM, Cullis PR. Cholesteryl hemisuccinate exhibits $\mathrm{pH}$ sensitive polymorphic phase behavior. Biochim Biophys Acta. 2000;1463:107114. doi:10.1016/S0005-2736(99)00186-8

46. Carafa M, Di Marzio L, Marianecci C, et al. Designing novel pHsensitive non-phospholipid vesicle: characterization and cell interaction. Eur J Pharm Sci. 2006;28:385-393.

47. Tesan FC, Portillo MG, Moretton MA, et al. Radiolabeling and biological Characterization of TPGS-based nanomicelles by means of small animal imaging. Nucl Med Biol. 2017;44:62-68. doi:10.1016/j.nucmedbio.2016.09.006

48. Melendez-Alafort L, Nadali A, Zangoni E, et al. Biokinetic and dosimetric studies of $188 \mathrm{Re}$-hyaluronic acid: a new radiopharmaceutical for treatment of hepatocellular carcinoma. Nucl Med Biol. 2009;36(6):693-701. doi:10.1016/j.nucmedbio.2009.04.006

49. Lepareur N, Lacoeuille F, Bouvry C, et al. Rhenium-188 labeled radiopharmaceuticals: current clinical applications in oncology and promising perspectives. Front Med (Lausanne). 2019;6:132. doi:10.3389/fmed.2019.00132

50. Hasanzadeh L, Kazemi Oskuee R, Sadri K, et al. Green synthesis of labeled $\mathrm{CeO}_{2}$ nanoparticles with ${ }^{99 \mathrm{~m}} \mathrm{Tc}$ and its biodistribution evaluation in mice. Life Sci. 2018;212:233-240. doi:10.1016/j.lfs.2018. 10.010

51. Mirkovic M, Radovic M, Stankovic D, et al. (99m) Tc-bisphosphonate-coated magnetic nanoparticles as potential theranostic nanoagent. Mater Sci Eng C Mater Biol Appl. 2019;102:124-133. doi:10.1016/j.msec.2019.04.034

52. Wang J, Zhang L, Peng F, Shi X, Leong D. Targeting endothelial cell junctions with negatively charged gold nanoparticles. Chem Mater. 2018;30:3759-3767.

53. Peng F, Tee J, Seyawati M, et al. Inorganic nanomaterials as highly efficient inhibitors of cellular hepatic fibrosis. ACS Appl Mater Interfaces. 2018;10(38):31938-31946. doi:10.1021/acsami.8b10527
54. Tay C, Setyawati M, Leong D. Nanoparticle density: a critical biophysical regulator of endothelial permeability. ACS Nano. 2017;11 (3):2764-2772. doi:10.1021/acsnano.6b07806

55. Setyawati M, Tay C, Bay B, Leong D. Gold nanoparticles induced endothelial leakiness depends on particle size and endothelial cell origin. ACS Nano. 2017;11(5):5020-5030. doi:10.1021/acsnano.7b01744

56. Setyawati M, Tay $\mathrm{C}$, Chia $\mathrm{S}$, et al. Titanium dioxide nanomaterials cause endothelial cell leakiness by disrupting the hemophilic interaction of VE-cadherin. Nat Commun. 2013;4:1673. doi:10.1038/ ncomms 2655

57. Peng F, Setyawati M, Tee J, et al. Nanoparticles promote in vivo breast cancer cell intravasation and extravasation by inducing endothelial leakiness. Nat Nanotechnol. 2019;14(3):279-286. doi:10.1038/s41565-018-0356-z

58. Setyawati M, Mochalin V, Leong D. Tuning endothelial permeability with functionalized nanodiamonds. ACS Nano. 2016;10(1):11701181. doi:10.1021/acsnano.5b06487

59. Tee J, Setyawati MI, Peng F, et al. Angiopoietin-1 accelerates restoration of endothelial cell barrier integrity from nanoparticle-induced leakiness. Nanotoxicology. 2019;13(5):682-700. doi:10.1080/1743 5390.2019.1571646

60. Jin H, Pi J, Zhao Y, et al. EGFR-targeting PLGA-PEG nanoparticles as a curcumin delivery system for breast cancer therapy. Nanoscale. 2017;9(42):16365-16374. doi:10.1039/C7NR06898K

61. Wang G, de Kruijff RM, Abou D, et al. Pharmacokinetics of polymersomes composed of poly (butadiene-ethylene oxide); healthy versus tumor-bearing mice. J Biomed Nanotechnol. 2016;12 (2):320-328. doi:10.1166/jbn.2016.2178

62. Cao J, Wei Y, Zhang Y, Wang G, Ji X, Zhong Z. Iodine-rich polymersomes enable versatile SPECT/CT imaging and potent radioisotope therapy for tumor in vivo. ACS Appl Mater Interfaces. 2019;11 (21):18953-18959. doi:10.1021/acsami.9b04294

63. Zhang H, Liu G, Zeng X, et al. Fabrication of genistein-loaded biodegradable TPGS-b-PCL nanoparticles for improved therapeutic effects in cervical cancer cells. Int J Nanomedicine. 2015;10:24612473. doi:10.2147/IJN.S78988

64. Cheng X, Zeng X, Li D, et al. TPGS-grafted and acid-responsive soy protein nanogels for efficient intracellular drug release, accumulation, penetration in 3D tumor spheroids of drug-resistant cancer cells. Mater Sci Eng C Mater Biol Appl. 2019;102:863-875. doi:10.1016/ j.msec.2019.05.017

65. Collnot EM, Baldes C, Schaefer UF, Edgar KJ, Wempe MF, Lehr CM. Vitamin E TPGS P-Glycoprotein inhibition mechanism: influence on conformational flexibility, intracellular ATP levels, and role of time and site of access. Mol Pharm. 2010;7(3):642-651. doi: $10.1021 / \mathrm{mp} 900191 \mathrm{~s}$
International Journal of Nanomedicine

\section{Publish your work in this journal}

The International Journal of Nanomedicine is an international, peerreviewed journal focusing on the application of nanotechnology in diagnostics, therapeutics, and drug delivery systems throughout the biomedical field. This journal is indexed on PubMed Central, MedLine, CAS, SciSearch ${ }^{\mathbb{B}}$, Current Contents ${ }^{\mathbb{B}} /$ Clinical Medicine, $^{2}$
Journal Citation Reports/Science Edition, EMBase, Scopus and the Elsevier Bibliographic databases. The manuscript management system is completely online and includes a very quick and fair peer-review system, which is all easy to use. Visit http://www.dovepress.com/ testimonials.php to read real quotes from published authors. 